\title{
The "Rationality" of Survey-Based Inflation Forecasts
}

\author{
R. W. HAFER and DAVID H. RESLER
}

$\mathbf{T}$

HE notion that economic agents rationally form their expectations about future economic events has emerged as a critically important hypothesis with profound implications for macroeconomic policy. For example, modem hypotheses relating to the Phillips curve emphasize that it is the departure of actual inflation from expected inflation that cause any shortrun trade-off that may exist between inflation and unemployment. Consequently, empirical tests of many macrotheoretic models require the identification not only of directly observable phenomena, such as inflation and unemployment, but also of expectations or anticipations of these phenomena.

The measurement of generally nonobservable phenomena, such as inflation expectations, poses a diffi cult challenge in constructing empirical tests for macro models that include such variables. It is first necessary to identify an inflation expectations proxy that is consistent with the assumptions of the underlying model. As a result, tests of theories, such as the natural rate hypothesis, that employ proxy measures for inflation expectations (such as autoregressive procedures) are joint tests of both the underlying theory and the validity of the expectations proxy.

Presumably, autoregressive procedures are used because they are less costly than opinion surveys. When survey-based data on inflation expectations are readily available, this cost argument loses some of its force. Nevertheless, it is important to determine which of the two measures is appropriate for testing various economic theories; that is, whichever measure conforms most closely to the requirements of the underlying theory becomes the measure of choice. For instance, tests of rational expectations models should first establish that the measures of expectations conform to the criteria of rationality. This paper examines whether one particular set of survey data - the Livingston data - meets specified criteria of rationality. ${ }^{1}$

${ }^{1}$ For examples of studies dealing with the measurement and effects of inflation expectations, see John A. Carlson, "A Study of Price Forecasts," Annals of Economics and Social Measurement (June 1977), pp. 27-56; Stephen Figlewski and Paul Wachtel, "The Formation of Inflationary Expectations," Review of Economics and Statistics (forthcoming); Rodrey L. Jacobs and Robert A. Jones, "Price Expectations in the United States; 1947-1975," American Economic Review (June 1980), pp. 269-77; Edward Kane and Burton G. Malkiel, "Autoregressive and Nonautoregressive Elements in Cross-Section Forecasts of Inflation," Econometrica (January 1976), pp. 1-16; Donald J. Mullineaux, "On Testing for Rationality: Another Look at the Livingston Price Expectations Data," Journal of Political Economy (April 1978), pp, 329-36; Duuglas K. Pearce, "Comparing Survey and hational Measures of Expected Inflation: Forecast Perfomance and Interest Rate Effects," Joumal of Money, Credit and Banking (November 1979), pp. 447-56; James $E$. Pesando, "A Note on the Rationality of the Livingston Price Expectations Data," Journal of Political Economy (August 1975), pp. 849-58; and Stephen J. Turnovsky, "Empirical Evidence on the Formation of Price Expectations," Journal of the American Statistical Association (December 1975), pp. 1441-54. 


\section{Tests of Rational Expectations}

The hypothesis of rational inflation expectations, pioneered by John Muth, holds that expectations about future inflation are formed in a mamner that fully reflects all currently avalable and relevant information." Stated somewhat differently, the observed rate of inflation differs from the expected rate of inflation only by some random error. Thus, the rationality hypothesis can be stated algebraically as:

(1) $\pi_{\varepsilon}={ }_{1+1} \pi_{t}^{\hat{t}}+u_{t}$,

where $\pi_{t}$ is the actual rate of inflation during period $t, t-1 \pi_{t}^{p}$ is the rate of inflation expected at time $t-1$ for period $t$, and $u_{t}$ is a randon variable with mean zero and variance $\sigma_{t}^{4}{ }^{3}$

Expressed in this form, i.e., inflation expectations are unbiased estimates of observed inflation, the rationality hypothesis can be tested empirically by estimating the equation,

(2) $\pi_{\mathrm{r}}=\mathrm{B}_{0}+\mathrm{B}_{\mathrm{r}-\mathrm{z}} \pi_{\mathrm{i}}^{\mathrm{b}}+\mathrm{ul}_{\mathrm{i}}$,

where $t-1 \pi_{t}^{a}$ represents the survey-based expected inflation rate for period $t$ made at period $t-1$. The notion of rational expectations, then, corresponds to the joint hypothesis that $B_{4}=0$ and $B_{1}=1$. In addition, $u$. should exhibit no evidence of autocorrelation.

Pesando and Figlewski and Wachtel subjected the Livingston expectations series to this test of rationality. ${ }^{4}$ Pesando was unable to reject the joint hypothesis using consensus inflation forecasts from each survey for the periods 1959-1969 and 1962-1969. Figlewski and Wachtel, however, were able to reject the null hypothesis using a pooled time series/cross-section sample of 1,864 individual forecasts for the period 1947-1975.

An additional criterion for rationality requires that inflation forecasts be efficient; in other words, the process by which inflation expectations are formed should be identical to the process that actually generates observed inflation. Consequently. any evidence suggesting that some of the relevant information set is not being fully (i.e., efficiently) utilized would indicate rejection of rationality. Pesando tested this notion of rationality by hypothesizing that both the expectations of inflation and inflation itself are described by the history of inflation. Mathematically,

2Tohn F. Muth, "Rational Expectations and the Theory of Price Movements," Econometrica (July 1961), pp. 315-35.

${ }^{3}$ Alternatively, equation (1) can be rewritten as $\left(\pi_{t}-{ }_{1.1} \pi_{6}^{*}\right)$ - $\mathrm{u}_{\mathrm{t}}$; that is, any departure of actual from expected inflation is a random variable with mean zero and variance, $\sigma_{\mathrm{a}}$.

4Pesando, "A Note on the Rationality ..." " and Figlewski and Wachtel, "The Formation of Inflationary Expectations." this interpretation of rationality can be expressed as.

$$
\begin{aligned}
& \text { (a) } \pi_{4}=\sum_{i=3}^{n} B_{4} \pi_{t .1}+\mu_{3 t} \\
& \text { (b) } \quad{ }_{t-1} \pi_{t}^{o}=\sum_{j=1}^{p} B_{i}^{i} \pi_{t \cdot j}+\mu_{i r} \text {. }
\end{aligned}
$$

Efficiency requires that $B_{i}=B_{i}^{\prime}$ for all $i, \ldots, n$ Pesando, Carlson, and Mullineaux directly tested the efficiency of the Livingston inflation forecasts by estimating equation (3) and then applying an F-test to the sum of the squared residuals. " Pesando was not able to reject the efficiency criterion at standard confdence levels for the period 1959-1969. Carlson, using the same time period but a revised version of the Livingston data, found that the inflation forecasts do not satisfy the efficiency criterion."

Mullineanx, on the other hand, demonstrated that the error variances of equations (3a) and (3b) estimated by Pesando and Carlson are not homogeneous. Consequently, the F-test used by Pesando and Carlson is inappropriate. ${ }^{\top}$ Mullineaux proposed an alternative efficiency test that involves estimating the equation.

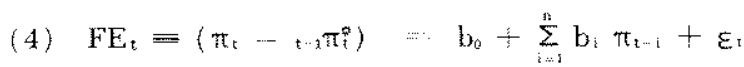

where $\varepsilon_{\mathrm{t}}=\mu_{1 \mathrm{t}}-\mu_{\mathrm{t} t}$. The forecast error $\left(\mathrm{FE}_{\mathrm{t}}\right)$ is re. gressed on past inflation rates known at the time the forecast was made." Efficiency requires that $\mathrm{FE}_{\mathrm{t}}$ be

see Pesando, "A Note on the Rationality. . ." This approach to testing for rationality is generally referred to as a "weakfom" test because it enpploys only information contained in the history of inflation. It should be noted, however, that fait ure to meet the weak-fom requirements of rationality sug gests that the forecast would also fail stronger forms of the test. For a discussion of weak-form and other types of tests. see John Rutledge, A Monetarist Model of Inflationary Expectations (Lexington: Lexington Books. 1974). In addition, equation (3) does not specify either the exact length of the lag on past inflation or the length of the period over which the inflation is observed. Pesando, Carlson, and Mulmeaux each used a 5-period lag on observed 6-month inflation rates This lag length will also be used in this paper.

"Carlson has noted that the numbers published by Livingston have been judgmentally revised. To circmivent this possible source of error, Carlson constructs a forecast series that is based on the actual responses received by Livingston. See Carlson, "A Study of Price Forecasts," for a more detailed discussion of his construction procednes.

-The Chow test used by Pesando and Carlson requires that the error terms $\mu_{t+}$ and $\mu_{t}$ be independently and identically dis. tributed. If the error terms are nof identically distributed (homogeneous variances), the Chow test is mappropriate. Mullineaux tests for variance homogeneity by using Bartetes test statistic and finds that the hypothesis of homogeneous variances is rejected at the five percent level of significance. See Mullineaux, "On Testing for Rationality ..., " pp. 331-32.

8Equation (4) is derived by subtracting equation (3b) from (3a). That is, $b_{3}=B_{1}-B_{1}^{\prime}$ for all i. Following Mullineaux. equation $(4)$ is estimated with a constant term $\left(b_{4}\right)$ instead of subsuming it into the error structure as Pesando and Carl. son did. 
unrelated to any information known at the time ( $\mathrm{t}-1)$ the forecast was formed. In other words, all the informational content of past inflation rates is fully utilized in forming expectations. Thus, the null hypothesis is that $b_{0}=0$ and $b_{i}=0$ for all $i_{2} \ldots, n$. In addition, efficiency requires that the error term be serially uncorrelated, or $\operatorname{Cov}\left(\varepsilon_{t_{1}} \varepsilon_{i}\right)=0$ for $t \neq \mathbf{i}^{9}{ }^{9}$ Using Carlson's version of the Livingston data, Mullineaux was unable to reject the efficiency hypothesis for the period 1959-1969. ${ }^{10}$

Pearce, using Carlson's data set and another test of efficiency, concluded that "the survey respondents did not efficiently use the information in the past history of the Consumer Price Index (CPI) when forming their expectations of inflation." 11 Thus, it appears that efficiency tests of the Livingston inflation expectations data are sensitive to the type of tests used, to the version of the Livingston data used, and to the time period examined.

This article demonstrates that these test results are also sensitive to assumptions about the length of the forecast horizon. Therefore, it is particularly important to determine the actual period over which Liv ingston respondents are making their forecasts. The nature of this problem can be illustrated by a careful review of the survey method.

\section{The Forecast Horizon and the Forecast Error}

Livingston conducts his survey each spring and fall, requesting respondents to indicate their predictions about a number of economic indicators including the CPI. For example, in the spring survey they are asked to predict what the level of the CPI will be in the following December and June. Because the questionnaires are mailed in April and ustally are returned in May, two interpretations can be made about the forecast horizon. If, as Carlson assumes, the survey respondents know only the April CPI, then they are implicitly predicting an 8-month rate-of-change (April to December) and a 14-month rate-of-change (April

9It should be noted that, although the heterogeneots vartance problem that plagued the Chow tests of Pesando and Carlson is alleviated here, the procedure employed does require the maintained hypothesis of independent errors.

10Mullineaux also found that for the data set used by Pesando (i.e. inflation forecasts inferred from the originally published versions of Livingston data), the lyypothesis of efficiency is rejected.

11Pearce, "Comparing Survey and Rational Measures...." p. 451. Peatce statistically analyzes the forecast errors obfained by using either the Livingston forecasts or forecasts generated from a continuously updated moving average model $[\mathrm{MA}(1)]$ of the monthly CPI series. to June of the following year). Alternatively, Jacobs and Jones argue that a more reasonable assumption is that the respondents actually know or have an accurate estimate of the May CPI. ${ }^{12}$ This, of course, means that the forecast CPI implies a 7 -month (or 13-month) rate of inflation.

The choice of the forecast horizon can affect the results of the bias and efficiency tests, especially if the forecast is interpreted loosely as a prediction of a steady inflation. Mullineaux and Resler each made this assumption; i.e., they assume that the prediction is a constant rate-of-change for any period within a given forecast horizon ${ }^{13}$ This assumption is often convenient and may not be inappropriate when the investigation focuses on the process that generates the forecast. It may pose problems, however, when efficiency tests, such as those represented by equation (4), are conducted.

Because the survey respondents are in fact, forecasting an inflation rate over a 7 - or 8-month horizon, it is desirable to evaluate equation (4) by calculating the forecast error over that time horizon. For example, $\mathrm{FE}_{\mathrm{t}}$ should be calculated by taking the difference between the actual rate of inflation occurring between April (or May) and December and the rate of inflation predicted for that period. This forecast error should be regressed against lagged inflation rates known to the forecaster as of April (or May). This approach differs from Mullineaux's procedure in which $\mathrm{FE}_{\mathrm{t}}$ was computed as of the time the next forecast was made (i.e., October). This approach seems inappropriate for evaluating the efficiency of the forecasts, especially since the forecasts exhibit expectations of accelerating inflation. The next section reevaluates the tests for bias and efficiency in light of these new timing assumptions.

\section{Empirical Results}

To investigate the importance that assumptions about the forecast horizon have on tests for bias and

\footnotetext{
12Jacobs and Jones, "Price Expectations in the United States:
$1947-1975 . "$

13 This essentially requires that inflation forecasts are linear. Thus, changes from one point to another within the forecast horizon will not be distinguishable, If, however, inflation expectations are not linear over different time horizons (e.g., 6 or 8 months), then the assumption of a steady rate of inflation prediction is vitiated. The fact that the 14-month forecasts are greater than the 8-month forecasts in 38 out of 40 observations from 1959-1978 suggests that the assumption of a constant rate of inflation within the 8 - or 14 -month periods may not be appropriate. See Mullineaux, "On Testing for Rationality", fr.. 3. See also, David H. Resler, "The Formation of Inflation Expectations," this Review (April 1980), pp. 2-12.
} 
efficiency (and hence rationality), the three altemative forecast horizons discussed in the preceding section are utilized in direct empirical comparisons. Based on these forecast horizons, three forecast error series are calculated and employed in the efficiency tests reported below. To reiterate, these altemative $\mathrm{FE}_{\mathrm{t}}$ series are determined by assuming an April-October forecast horizon (Mullineaw), a May-December forecast horizon (Jacobs-Jones), and an April-December forecast horizon. All tests use Carlson's version of the Livingston data (i.e., sample average CPI forecasts from which the expected inflation rate is generated). To facilitate a comparison with previous research, the following sample periods are used: 1959-1969, 19591978, and 1959-1978 excluding the 1971-1973 period of price controls of various phases. ${ }^{14}$

To test for bias in the inflation forecasts, equation (2) is estimated and an F-test on the joint hypothesis that $B_{0}=0$ and $B_{1}=1$ is conducted for each of the alternative forecast horizons. ${ }^{15}$ The F-values calculated for this test are presented in table 1 , and allow rejection of the null hypothesis at the 1 percent level, irrespective of the sample period chosen. This result contrasts directly with Pesando's but is consistent with the findings of Figlewski and Wachtel, who found the Livingston data to be biased. ${ }^{16}$ An examination of the individual coefficients, $B_{\|}$and $B_{1}$, indicated that the joint hypothesis is rejected primarily because $B_{1}$ exceeds unity for all the sample periods. Nevertheless, the results indicate a tendency for $B_{1}$ to decline toward unity as more recent observations are added to the sample, suggesting that forecasters gradually adjusted to the accelerating inflation of the $1960 s$ and early $1970 s^{17}$

Table 2 presents additional information on the accuracy of the inflation expectations series. Although the root-mean-squared error and mean error statistics

14his trumeated 1959-1978 sample period was chosen to exclude observations of forecasts errors that occurred duning the period of wage and price controls. It seems reasonable that forecasters would have encotntered considerably more difficulty in forecasting inflation during this period, since the controls were applied innevenly and gradually relaxed at inpredicted intervals.

15To facilitate computation of the appropriate F-statistics, equation (2) was modified stightly. Specifically, subtracting 1- $-\pi_{i}^{*}$ from each side of (2) prodices:

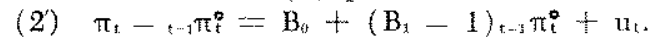

The null hypothesis then implies that the estinated slope and intercept of equation $\left(2^{\prime}\right)$ be jointly equal to zero.

rePesando, "A Note on the Rationality..." and Figlewski and Wachtel, "The Formation of Inflationary Expectations,"

1i Ir studies of the process by which inflation forecasts are generated, more definitive evidence indicates that this process has changed over time. For more detail about this evidence, see Donald J. Mullineanx, "Inflation Expectations and Money"

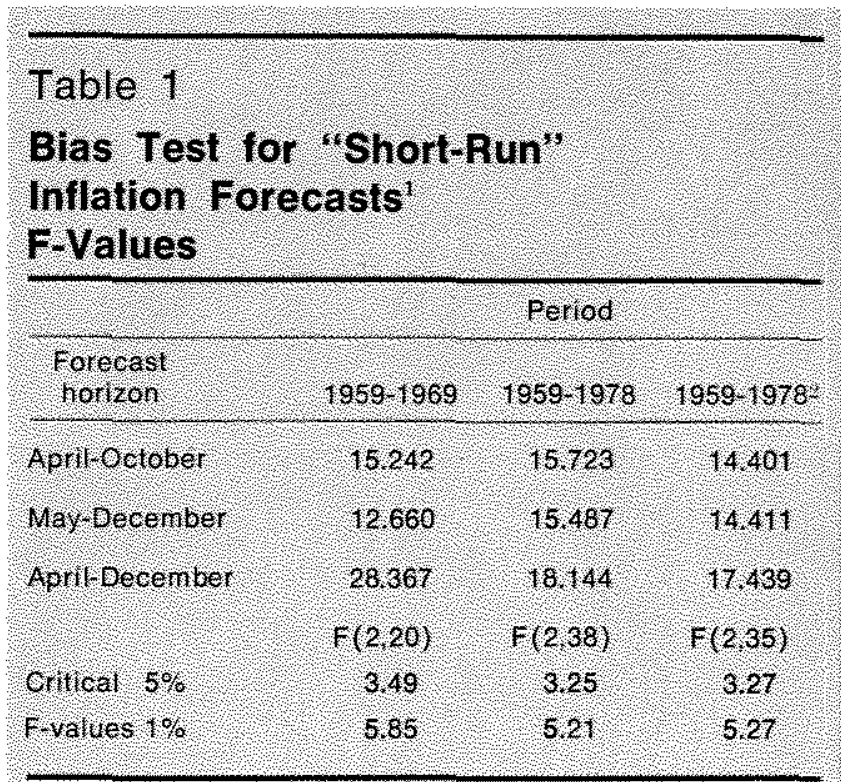

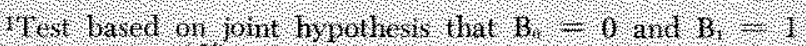
it equation 22 ?

This peried odudes the 19741973 prie control teats.

vary only slightly between forecast horizons, the Theil statistics indicate that the fraction of forecast error due to bias is reduced somewhat by using the May-December horizon. It is interesting to note that. of all of the horizons examined, the April-December assumption continually vields statistics suggesting greater problems with bias than variance or covariance in the forecasts. ${ }^{18}$

Although unbiased forecasts satisfy one criterion for rationality, it is common to find properties of bias in other non-survey-based inflation forecasts. For instance, Lombra and Moran note that, while the Federal Reserve Board staffs forecasts of nominal GNP are unbiased, its forecasts of GNP's real and inflation components show evidence of systematic errors. ${ }^{19}$

It is possible that inflation forecasts can show evidence of systematic bias yet still be characterized as

Growth in the Unted States," American Economic Review (March 1980), pp. 149-161, and Resler, "The Fomation of Inflation Expectations."

ibfor a description of this methodology, see Heni Theil, Applied Economic Forecasting (Ansterdam: North Holland Publishing Co., 1971), pp. $26-32$.

"Raymond Lombra and Michael Moran, "Policy Advice and Policy Making at the Federal Reserve," Camestie-Rochester Conference Series on Public Policy 13, 1980, p. 20. For evidence that other forecasts similarly underestimate inflation and over-estinate real output, see V. Zarnowitz, "An Analysis of Amual and Multiperiod Ouarterly Forecasts of Aggregate Income, Output, and the Price Level," Jotrmal of Business $(1979)$, p. 133. 


\section{Table 2}

\section{Analysis of the "Short-Run" Forecast Errors'}

\begin{tabular}{|c|c|c|c|c|c|c|}
\hline \multirow{2}{*}{$\begin{array}{l}\text { Forecast } \\
\text { horizon } \\
\text { assumption }\end{array}$} & \multirow{2}{*}{ Sample } & \multirow[b]{2}{*}{ RMSE } & \multirow{2}{*}{$\begin{array}{l}\text { Uear } \\
\text { error }\end{array}$} & \multicolumn{3}{|c|}{ Theil statistics } \\
\hline & & & & U? & 4 & 4 \\
\hline \multirow[t]{3}{*}{ April-october } & 1959.69 & 1,383 & 0911 & 0.464 & 0360 & 0.206 \\
\hline & 195978 & 2151 & 1,324 & 0.379 & 0,226 & 0,394 \\
\hline & 195978 & 2,053 & 1270 & 0,383 & 0.223 & 0.394 \\
\hline \multirow[t]{3}{*}{ May-December } & 1959.69 & 1344 & 0.858 & 0.408 & 0.347 & 0.246 \\
\hline & $1959-78$ & 2.317 & 1,414 & 0,372 & 0252 & 0.375 \\
\hline & 195978 & 2214 & $\lcm{1356}$ & 0,375 & 0252 & 0,373 \\
\hline \multirow[t]{3}{*}{ Apriloecember } & 195969 & 1.307 & 0.934 & 0.513 & 0,344 & 0.143 \\
\hline & $1959-78$ & 2,01 & 1,355 & 0,416 & 0.210 & 0,374 \\
\hline & $1959-782$ & 1,962 & 1261 & 0,43 & 0.203 & 0.384 \\
\hline
\end{tabular}

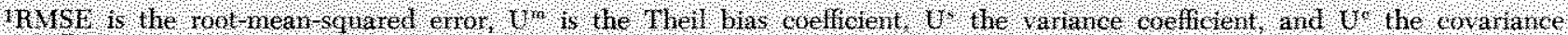
coefficient

2 Omits he 19711070 , tice control years.

"weakly" rational in the sense that the forecasters efficiently utilize all information contained in the history of inflation, To implement this efficiency test, $\mathrm{FE}_{\mathrm{t}}$ is calculated for each forecast horizon and used to estimate equation (4).

Because acceptance of the efficiency hypothesis in the present context requires that $b_{i}=0$ for all $i(i=1$, $\ldots, n)$ and that the estimated relationships indicate no evidence of serial correlation, the statistics of primary interest are the reported $F$-values and the Durbin-Watson and Durbin-h statistics. The reported F-value is pertinent for testing the joint hypothesis that all the $b_{i}(i=1, \ldots, 5)$ are concurrently zero. Both the Durbin-Watson and Durbin-h statistics test for the presence of serial correlation. Although the DurbinWatson statistic is usually appropriate, Durbin has shown that the $h$ statistic is more efficient when the set of independent variables includes a lagged dependent variable..$^{20}$ Because Mullineaux has interpreted equation (4) as containing a lagged dependent variable, both statistics are reported.

Ordinary least squares estimates of equation (4), using the alternative $\mathrm{FE}_{\mathrm{t}}$ series and sample periods, are presented in table 3 . These results differ consider-

\footnotetext{
20See James Durbin, "Testing for Serial Correlation in Least Squares Regression When Some of the Regressors are Lagged Dependent Vatiables," Econometrica (May 1970), pp. 410-21.
}

ably from those of Mullineaux, and they highlight the importance of specifying the time period over which $\mathrm{FE}_{\mathrm{t}}$ is calculated. If $\mathrm{FE}_{\mathrm{t}}$ is evaluated at the end of the period over which the respondents were forecasting inflation (e.g., December), the efficiency hypothesis is rejected in all but one instance. The results for the three different time periods are now discussed in greater detail.

Turning first to the $1959-1969$ period, the reported F-statistic for the May-December and the AprilOctober forecast horizons indicates that the efficiency criterion is satisfied. Recalling that the April-October horizon corresponds to the assumption made by Mullineaux, these results are essentially consistent with his. The Durbin-h statistic for the April-October horizon, however, indicates the presence of negative serial correlation, even though the Durbin-Watson statistic falls within the indeterminate range. ${ }^{21}$ Since

21 For purposes of comparison, Mullineatux's estimation results are presented here:

$$
\begin{aligned}
& \left(\pi_{t}-{ }_{t-1} \pi_{t}^{*}\right)=-0.232+0.237 \pi_{t-1}-0.051 \pi_{t-2}+0.251 \pi_{t} \\
& (1.91)(1.44)(0.27) \quad(1.36) \\
& +0.050 \pi_{t-1}+0.083 \pi \\
& (0.25) \quad(0.48) \\
& \overline{\mathrm{R}}^{2}=0.102, \mathrm{~h}=1.89, \mathrm{~F}=1.48 \text {. }
\end{aligned}
$$

The difference between Mullineaux's results and those in table 3 may well be due to the use of different computer algorithms. As such, the difference between the Durbin-h values may not be representative of true differences in the respective residual processes. 


\section{Table 3}

Efficiency Test Results

\begin{tabular}{|c|c|c|c|c|c|c|c|c|c|c|c|}
\hline \multirow{2}{*}{$\begin{array}{l}\text { Forecast } \\
\text { hortzon }\end{array}$} & \multicolumn{6}{|c|}{ coefticlents } & \multicolumn{5}{|c|}{ Summary statistios } \\
\hline & $\mathbf{b}_{\mathrm{s}}$ & $b_{1}$ & b. & $b_{3}$ & $b_{1}$ & $b_{2}$ & $\bar{R}^{2}$ & $\mathrm{DW}, / \mathrm{K}$ & S.E.E & $\mathrm{F}$ & $F(05.01)$ \\
\hline \multicolumn{12}{|c|}{$1959-1969$} \\
\hline April-October & $\begin{array}{l}0,244 \\
(0.46)\end{array}$ & $\begin{array}{r}0.244 \\
(1.48)\end{array}$ & 0.049 & $\begin{array}{r}0,254 \\
(1,37)\end{array}$ & $\begin{array}{l}0.050 \\
(0.26)\end{array}$ & 0,083 & 0.91 & $261 / 226$ & 100 & 154 & \\
\hline May-December & $\begin{array}{r}0.493 \\
(1,02)\end{array}$ & $(1,19)$ & $\begin{array}{l}0.114 \\
(0,61)\end{array}$ & $(0,215$ & $\begin{array}{r}0,114 \\
(0.58)\end{array}$ & $\begin{array}{l}0,041 \\
(0,22)\end{array}$ & 024 & $225 / 091$ & 0,92 & 236 & 285,444 \\
\hline April-December & $\begin{array}{r}0.345 \\
(0.88)\end{array}$ & $\begin{array}{r}0218 \\
(179)\end{array}$ & 0,051 & 0.285 & $\begin{array}{r}0.019 \\
(0,13)\end{array}$ & 0.061 & 0,38 & $1,85 / 043$ & 0,74 & 3.52 & \\
\hline \multicolumn{12}{|c|}{$1959-1978$} \\
\hline Apriloctober & $\begin{array}{r}0,695 \\
(153)\end{array}$ & $\begin{array}{l}0397 \\
(282)\end{array}$ & $\begin{array}{l}0.003 \\
(0.02)\end{array}$ & 0,000 & 0,261 & $\begin{array}{l}0,02 \\
(071)\end{array}$ & 0.20 & $2,14 / 0.97$ & 1.54 & 2.92 & \\
\hline May Decembet & $\begin{array}{r}0,442 \\
(1,01)\end{array}$ & $(0,435)$ & $\begin{array}{r}0.133 \\
(0.81)\end{array}$ & $\begin{array}{r}0,113 \\
(0,64)\end{array}$ & $\begin{array}{r}04436 \\
(2,43)\end{array}$ & $(0,200$ & 037 & $1.98 / 0.12$ & 1,47 & 5.68 & $2,49,3.51$ \\
\hline Aptil December & $\begin{array}{l}0,717 \\
(174)\end{array}$ & $\begin{array}{l}0,368 \\
(288)\end{array}$ & $\begin{array}{l}0.035 \\
(0.22)\end{array}$ & 0.058 & $\begin{array}{r}0.362 \\
(2.21)\end{array}$ & $\begin{array}{l}0,60 \\
(123)\end{array}$ & 0,26 & $177 / 101$ & 1,40 & 3.76 & \\
\hline \multicolumn{12}{|c|}{ (omitting $1971-73)$} \\
\hline Apriloctober & $\begin{array}{r}0,649 \\
(1,44)\end{array}$ & $\begin{array}{l}0,300 \\
(2,06)\end{array}$ & $\begin{array}{l}0.062 \\
(0.35)\end{array}$ & $\begin{array}{r}0,052 \\
(0,28)\end{array}$ & 0.257 & $\begin{array}{r}0.082 \\
(0.56)\end{array}$ & 014 & $2.21 /-1,22$ & 1.51 & 216 & \\
\hline May-December & $\begin{array}{r}0,414 \\
(0,96)\end{array}$ & $(2.43)$ & $(1.06)$ & $\begin{array}{l}0.051 \\
(0.29)\end{array}$ & $\begin{array}{l}-0.412 \\
(2.31)\end{array}$ & $\begin{array}{l}0,155 \\
(1.07)\end{array}$ & 0.34 & $2.01 /-0.05$ & 150 & 4.43 & $2.54,3.73$ \\
\hline April-December & $\begin{array}{l}0.668 \\
(1.69)\end{array}$ & $\begin{array}{r}0.269 \\
(2,11)\end{array}$ & $\begin{array}{r}0.098 \\
(0,63)\end{array}$ & 0,009 & $\begin{array}{l}0,361 \\
(2,26)\end{array}$ & $\begin{array}{r}0.140 \\
(1.10)\end{array}$ & 0.24 & $1.80 / 0.90$ & 1.33 & 3.14 & \\
\hline
\end{tabular}

1 Test results based on equation (4).

"Valies in parentheses represent absolute values of t-statistics:

$3 \overline{\mathrm{R}}^{2}$ is the coefficient of detemination corrected for degrees of freedom, $D$. $W$. is the Durbin-Watson statistic; $h$ is the Durbin-h statistic; S.E.E. is the standard error of the equation; $F$ is the calculated F-value to test the joint hypothesis that all

$b_{3}(i=1, \ldots, 5)$ equal zero; and $\mathrm{F}^{\circ}$ represents the relevant critical $\mathrm{K}_{\text {-value. }}$

efficiency requires no serial correlation among the residuals, the hypothesis of efficiency for the AprilOctober horizon remains unresolved. Unlike these two forecast horizons, however, the results based on using the April-December assumption clearly permit rejection of the efficiency hypothesis."-2

In contrast to the results for the $1959-1969$ period, the hypothesis of efficiency is unambiguously rejected at the 5 percent level for each forecast horizon examined during the entire 1959-1978 sample period. The hypothesis is also rejected at the 1 percent level for the May-December and April-December horizon

2y shotld be recalled that the April-December forecast horizon does not require the special assumptions necessary to construct the competing forecast error series. We know that Livingston supplies the April CPI to the survey recipients and specifically asks for their December CPI forecast. periods. Based on these test results, the period from 1959-1978 does not appear to be one in which Livingston forecasters, on average, efficiently utilized the information contained in the history of observed inflation rates.

Similarly, when the period of wage price controls is excluded, the efficiency criterion is not satisfied if the forecast error is calculated at the end of the forecast period (e.g., in December). For instance, when the forecast error is measured at the end of the period over which the forecast is made, the $F$-test permits a rejection of the efficiency hypothesis at the 5 percent level, ${ }^{33}$ The efficiency hypothesis is not re-

2 The efficiency hypothesis camot be rejected, however, at the 1 percent level when the 8-nonth (Akpril-December) forecast horizon is employed. 
jected only when the forecast error is evaluated in October (as in Mullineaux).

\section{Efficiency of the 12-Month Forecasts}

Most previous analyses of the Livingston intlation forecasts focus on the short-run (8-month) forecasts. Because the respondents are asked at each survey date to predict the level of the CPI for the following December and June, the forecasts embody both an 8 month and a 14-month (long-run) prediction of the inflation rate. This section examines the rationality of the 14-month forecasts.

The methodology used here slightly modifies the approach used for the 8-month forecasts. Specifically, the lagged inflation rates in equation (4) are now interpreted as occurring over 12 -month periods (again, observed in either April or October). This assumption requires that the estimation of these equations for the 14-month forecasts be modified.

Because the forecasts are made at 6 -month intervals, this new interpretation means that the first lagged term in equation (4) contains information that overlaps from the previous period, if all available observations are included in the estimation procedure. Such overlapping observations may introduce serial correlation into the equation. ${ }^{24}$ To avoid this problem, separate estimations of equations (2) and (4) are made for each semiannual observation of the 14 month forecast; that is, each sample period is split into two data sets, one consisting only of the June forecasts and the other consisting only of the December forecasts. With these modifications, equations (2) and (4) are estimated for the three time periods used in the previous section.

The analysis first examines the 14-month forecasts for bias. F-statistics were computed from the regressions of equation (2) for each semiannual forecast series over each sample period. These F-values, reported in table 4, again indicate that the forecasts are biased. Table 5 provides the statistics for Theil's analysis of the forecast errors. These results also show that 33-54 percent of the forecast error is due to bias. Nevertheless, as with the "short-run" forecasts, the portion due to bias declines as new data are added.

The efficiency test is then applied to the 14-month forecast errors. The forecast errors are consistently

\footnotetext{
${ }^{24}$ Introduction of serial correlation tends to bias the efficiency test toward rejecting the mull hypothesis. Recall that an additional criterion for efficioncy is that the estimation be free of autocorrelation.
}

\section{Table 4}

Blas Test for 14 Month Inllation Forecasts? F-Values

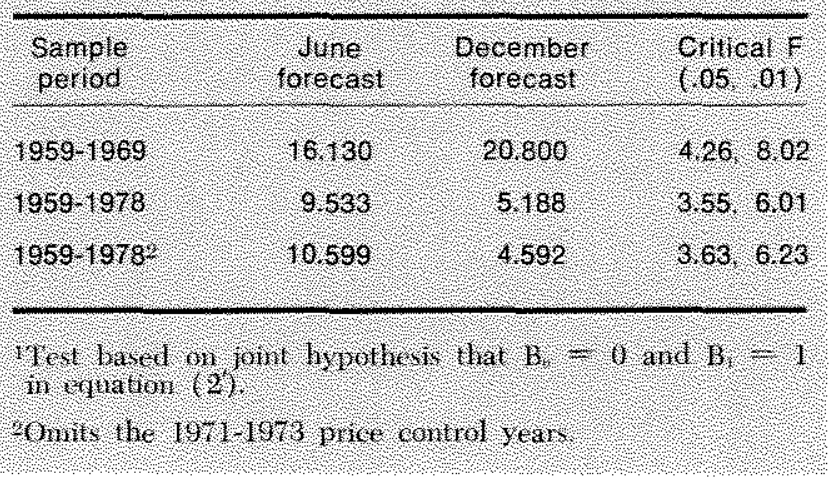

measured as of the end of the period over which the forecast was made. The F-statistics and the DurbinWatson statistics for these equations are reported in table 6."5 In contrast to the 8-month (April-December) inflation forecasts, the results for the 14-month forecasts do not permit rejection of the efficiency hypothesis. Because halving the sample period severely reduces the degrees of freedom, these results should be nterpreted with considerable caution. Nevertheless, the F-statistics suggest that the errors in the 14-month forecasts are not correlated with observations of past inflation available at the time the forecast was made. The Durbin-Watson statistics, however, indicate that the hypothesis of no serial correlation can nether be rejected nor accepted. Thus it appears that based on the F-test, the 14-month forecasts comply with the efficiency criterion.

These contrasting results for the 8-month and 14 month forecast horizons cast some doubt on the findings that the Livingston forecasts are not formed efficiently. This disparity may indicate that forecasters are better able to anticipate longer-term movements in economic variables, such as inflation, relative to explaining the short-term vagaries of the time series. For instance, if the actual rate of inflation is accelerating within the 14-month period, the forecaster may be able to forecast efficiently the overall rate of change but not be able to forecast the rate within shorter sub-periods.

\footnotetext{
25The Durbin-h statistic is not approprizte for small sanples (n<30). On this point, see I. Johnston Econometric Methods, and ed. (New York: McGraw-Hill, 1971).
} 


\section{Table 5}

\section{Analysis of 14-Month Forecast Errors ${ }^{1}$}

\begin{tabular}{|c|c|c|c|c|c|c|}
\hline \multirow{2}{*}{$\begin{array}{l}\text { Forecast } \\
\text { horizon } \\
\text { assumplion }\end{array}$} & \multirow{2}{*}{$\begin{array}{l}\text { Sample } \\
\text { perlod }\end{array}$} & \multirow[b]{2}{*}{ RMSE } & \multirow{2}{*}{$\begin{array}{l}\text { Mean } \\
\text { error }\end{array}$} & \multicolumn{3}{|c|}{ Theil statistics } \\
\hline & & & & $0^{\mathrm{n}}$ & $u^{\prime}$ & $\mathrm{O}^{\circ}$ \\
\hline \multirow[t]{3}{*}{ Juno } & 195969 & 1,120 & 0.824 & 0540 & 0,337 & 0,123 \\
\hline & $1959-78$ & 1964 & 1298 & 0,436 & 0208 & 0,356 \\
\hline & $1959-78^{\circ}$ & 2022 & 1383 & 0,468 & 0222 & 0,310 \\
\hline \multirow[t]{3}{*}{ December } & $1959-69$ & 1,182 & 0,782 & 0.438 & 0.474 & 0.088 \\
\hline & 195978 & 2085 & 1190 & 0326 & 0198 & 0,477 \\
\hline & $1959,78 \%$ & 1976 & 1,130 & 0329 & 0,194 & 0,47 \\
\hline
\end{tabular}

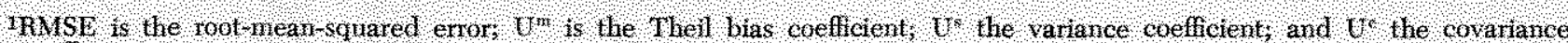
coefficient

20 mits the $1971-1973$ price eontrol years.

\section{Table 6}

\section{Efficiency Test Results: 14 -Month Forecasts ${ }^{1}$}

\begin{tabular}{ll} 
Sample period \\
\hline
\end{tabular}

W is the respective sample size, $F$ is the calculated $\mathrm{F}$ statisho, DW, s the Durbin-Walson test statistics and $F^{*}$ represents the televant citical F-value.

Ommits the $1971-1973$ price control years.

\section{Summary}

This paper has reexamined the rationality of the inflation forecasts contained in the Livingston survey data by emphasizing that the inflation forecast error should be calculated in a manner consistent with the forecast horizon used by the survey respondents. Specifically, empirical tests for bias and efficiency of the forecasts were employed to determine the effect that changes in the assumption about the forecast horizon have on the conclusions of previous investiga tions. The test for bias indicated that, regardless of the forecast horizon or the sample period used, the Livingston forccasts exhibited characteristics of bias.

The "efficiency" test suggested by Mullineaux was also employed. These test results indicate that over the period, 1959-1969, only one forecast horizon (April-December) could be judged unambiguously inefficient. When the 1959-1.978 period is examined, however, the results for each forecast horizon allow rejection of the efficiency hypothesis. When the period of wage-price controls is deleted from this sample period, only the April-October forecast horizon is judged efficient.

These findings imply that conclusions regarding the forecast efficiency (and, therefore, rationality) of the Livingston inflation expectations are sensitive to the period over which the forecast error is evaluated, Because the survey respondents are asked specifically to predict the level of the CPI for the following June or December, it seems appropriate that tests of 
efficiency be formulated to measure the forecast error only after the actual value of the predicted CPI becomes known. When this approach is used in conjunction with the assumption of either a May-December or April-December forecast horizon, the results indicate that the forecasters did not efficiently use the information available at the time of the survey in five out of six samples. This conclusion contrasts sharply with that reached when the forecast error is calculated at the time the forecasts are made (i.e., April or October).

Finally, evidence about the bias and efficiency of the 14-month forecasts indicates that these longer forecasts are efficient, even though, like the 8-month forecasts, they are apparently biased. Although the apparent disparity in the efficiency tests between the "short-" and "long-run" forecasts is somewhat puzzling, it suggests that the forecasters are more efficient at predicting longer term inflation trends than shortterm movements in the series.

The evidence presented here indicates that Carlson's sample average forecasts of the rate of CPI inflation in the Livingston data do not conform to two criteria of rationality. Consequently, the use of these data in empirical investigations of rational expectations models appears to have serious limitations. In addition, the observation that these survey-based inflation expectations fail to conform to rationality criteria suggests that adjustments in expectations evolve slowly. This further implies that, even if inflation forecasts are ultimately rational, fully anticipated short-run monetary policy actions may have important economic effects since inflation expectations adapt slowly. These and other possible implications of the apparent nonrationality of survey-based expectations deserve further study.

We would like to thank Don Mullineata and Doug Pearce for their helpful com. ments on an earlier draft of this paper. Their contributions in no way imply complete agreement with the opinions expressed herein.

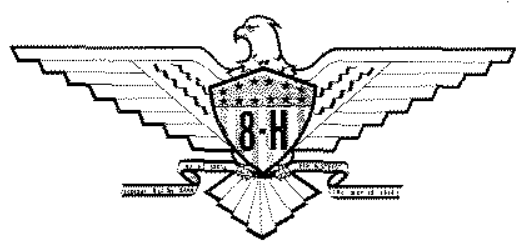

